\title{
Malposition of the Central Venous Catheter: A Diagnostic Dilemma
}

\author{
Sameer N. Desai, Santosh K. Dasar', Mithali V \\ Departments of Anaesthesia and ${ }^{1}$ Radiology, SDMCMSH, Dharwad, Karnataka, India
}

\section{Abstract}

A 50-year-old male was admitted to Intensive Care Unit with head and chest injury needed multiple central venous catheter (CVC) for the long-term intravenous access. Right internal jugular vein was cannulated uneventfully, and the tip of CVC was confirmed in the chest radiograph along the right border of the mediastinum. After few days, left subclavian vein was cannulated and the procedure was uneventful. However, the postprocedure Chest X-ray showed the $\mathrm{CVC}$ along the left border of mediastinum rather than the right border. Possibility of CVC in one of the tributaries of left brachiocephalic vein was thought. Due to uncertainty in position of left CVC, we inserted CVC in right-sided subclavian vein, which was in normal position along the right border of mediastinum. Left subclavian CVC was removed. Reviewing the patient's thoracic computed tomography scan revealed, patient had congenital anomaly and double superior vena cava that explained the abnormal course of left subclavian CVC along the left border of mediastinum.

Keywords: Central venous catheter, complications, malposition

\section{INTRODUCTION}

Central venous catheters (CVCs) are routinely used for long intravenous access in Intensive Care Unit (ICU). We report a case of malposition of CVC leading to diagnostic dilemma.

A 50-year-old male was admitted to ICU with head and chest injury needed multiple CVC for the long-term intravenous access. He had bilateral multiple rib fractures and right-sided hemothorax, for which an intercostal drain was inserted. Thoracic computed tomography (CT) scan with intravenous contrast was done to look for vascular injuries, which did not reveal any other injuries. Right-sided internal jugular vein was cannulated uneventfully, and the tip of CVC was confirmed in the chest radiograph along the right border of the mediastinum. The patient needed long-term intravenous access, hence change of CVC was planned 15 days later. Patient was placed supine with arms adducted. Under aseptic precaution, left subclavian vein was cannulated by Seldinger's technique in single attempt. Blood was freely aspirated from all the three ports of triple lumen CVC. Postprocedure chest X-ray revealed, CVC was along the left border of the mediastinum rather than along the right border [Figure 1]. The pressure waveform from CVC showed low amplitude

\begin{tabular}{|l|l|}
\hline \multicolumn{3}{|c|}{ Access this article online } \\
\hline Quick Response Code: & Website: \\
& www.ijccm.org \\
\hline
\end{tabular}

waves. Possibility of CVC entering in one of the tributaries of left brachiocephalic vein such as internal mammary vein was thought of as possibility. To differentiate among them, a lateral chest radiograph with intravenous contrast through the CVC was carried out. However, image quality was suboptimal. Since the position of left subclavian CVC was not confirmed, right subclavian vein was cannulated in single attempt. Chest radiograph confirmed the position of right $\mathrm{CVC}$ along the right border of the mediastinum [Figure 2]. Then, the left subclavian CVC was removed.

All the chest radiographs and CT scan chest were reviewed with a radiologist. An earlier performed thoracic CT scan with intravenous contrast revealed that patient had persistent left sided superior vena cava (SVC) along with right-sided SVC. Thus, the patient had double SVC (persistent left SVC [PLSVC]), and both of them were draining into the right atrium [Figures 3 and 4].

Address for correspondence: Dr. Sameer N. Desai, Department of Anaesthesia, SDMCMSH, Sattur, Dharwad - 580 009, Karnataka, India. E-mail: sameeeranaes@gmail.com

This is an open access article distributed under the terms of the Creative Commons Attribution-NonCommercial-ShareAlike 3.0 License, which allows others to remix, tweak, and build upon the work non-commercially, as long as the author is credited and the new creations are licensed under the identical terms.

For reprints contact: reprints@medknow.com

How to cite this article: Desai SN, Dasar SK, Mithali V. Malposition of the central venous catheter: A diagnostic dilemma. Indian J Crit Care Med 2017;21:235-7. 


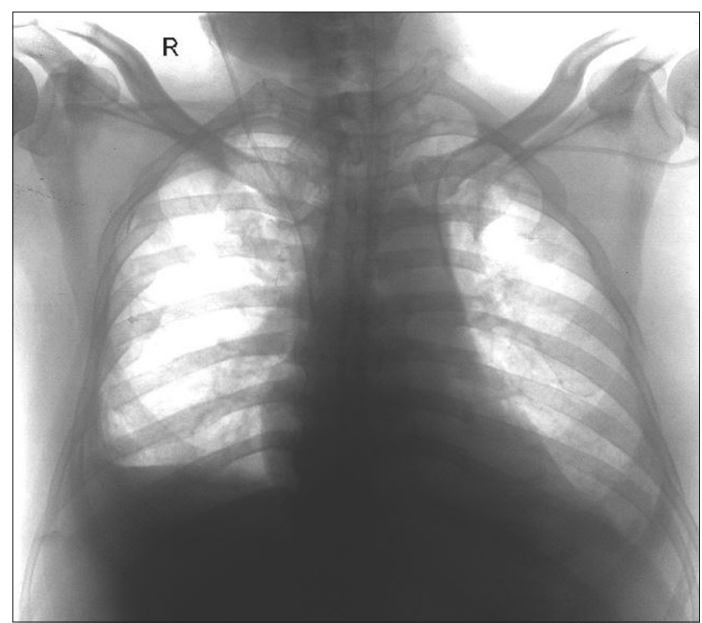

Figure 1: Right internal jugular central venous catheter along the right border of mediastinum and left subclavian central venous catheter along the left border of mediastinum

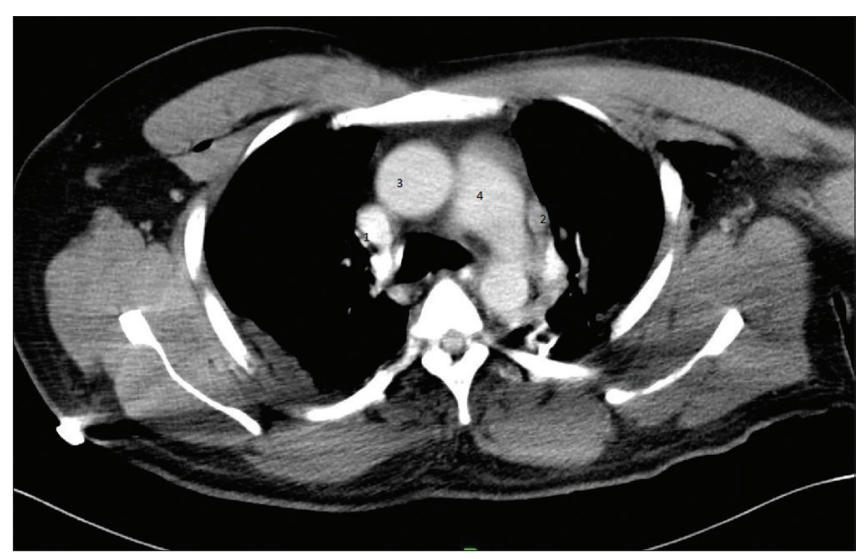

Figure 3: Contrast-enhanced thoracic computed tomography transverse view. 1: Right-sided superior vena cava, 2: Left-sided superior vena cava, 3: Aorta, 4: Pulmonary artery

\section{Discussion}

Normal position of the CVC will be along the right border of the mediastinum. The CVC that is outside normal course (along the left border of mediastinum) leads to suspicion of it either being intra-arterial, extravascular or in one of the tributaries of brachiocephalic vein. ${ }^{[1]}$ In our patient, the blood could be easily aspirated from all the three ports; hence, extravascular position was unlikely. Low-pressure waveform ruled out the possibility of intra-arterial placement. Hence, the possibility of CVC being in one of the tributaries of the left brachiocephalic vein such as internal mammary vein or superior intercostal or pericardiophrenic vein was considered. ${ }^{[2,3]}$ In the lateral view of chest radiograph, catheters in the internal mammary, pericardiophrenic and superior intercostal veins should occupy the anterior, middle, and posterior mediastinum, respectively. ${ }^{[4]}$ Hence, the lateral chest radiograph was done, which had poor image quality.

Although PLSVC is a relatively rare vascular anomaly (prevalence of $0.3 \%-0.5 \%$ in healthy individuals), it is the most

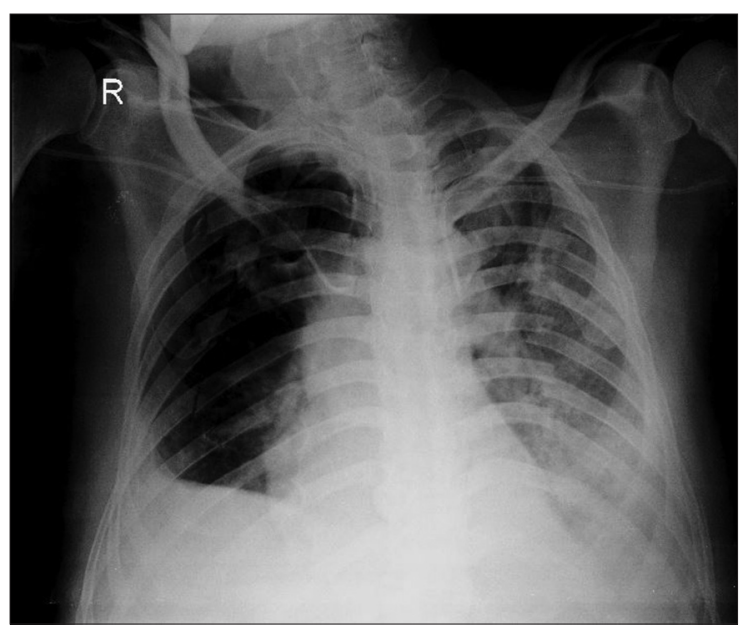

Figure 2: Chest X-ray anteroposterior right subclavian central venous catheter along the right border of mediastinum and left subclavian superior vena cava along the left border of mediastinum

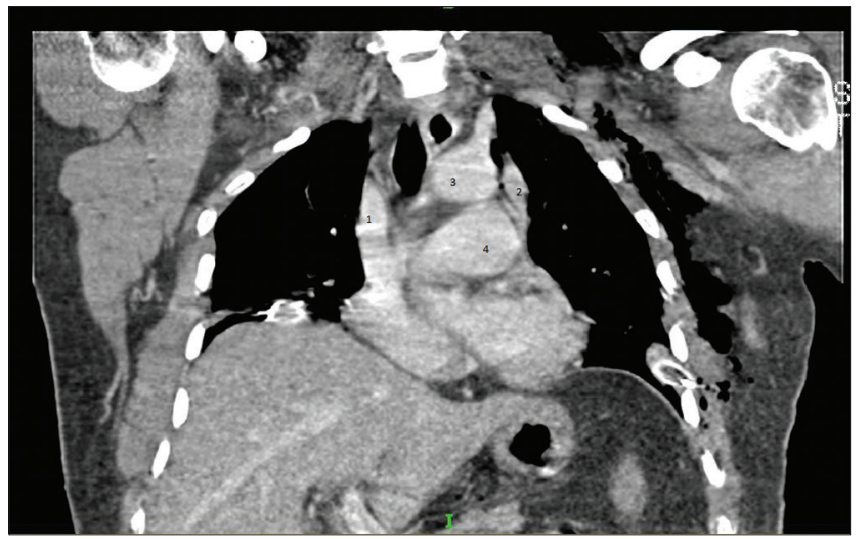

Figure 4: 1: Right-sided superior vena cava, 2: Left-sided superior vena cava, 3: Aorta, 4: Pulmonary artery

common congenital anomaly of the thoracic venous circulation. The thoracic embryonic venous system is composed of two large veins (the superior cardinal veins) which return blood from cranial aspect of embryo. ${ }^{[5]}$ The left common cardinal vein persists to form coronary sinus and oblique vein of the left atrium. During the $8^{\text {th }}$ week of gestation, an anastomosis forms between right and left superior cardinal veins resulting in the brachiocephalic vein. The cephalic portion of superior cardinal veins forms the internal jugular veins and the caudal portion forms the normal right-sided SVC, whereas the portion of the left superior cardinal vein caudal to the brachiocephalic vein normally regresses to become "ligament of Marshall." If this normal regression of the left superior cardinal vein fails to occur, a persistent left-sided vascular structure that empties into the coronary sinus results in condition PLSVC.

PLSVC may occur with a normal right-sided SVC (82\%) or without right SVC (as a single left-sided SVC). ${ }^{[6]}$ When a double SVC exists, the left SVC descends vertically, anterior, and to the left of the aortic arch and main pulmonary artery, then swings medially to enter the coronary sinus or right atrium. 
There are previous reports of an incidental diagnosis of a PLSVC with an abnormal left para-mediastinal course on $\mathrm{X}$-ray. ${ }^{[7,8]}$ Despite these reports the knowledge of this anomaly, its diagnosis and implications are not enough among the anesthesiologist and the intensive care specialist. This leads to many unnecessary investigations and removal of $\mathrm{CVC}$ for the fear of being in abnormal position. If double SVC is confirmed, most of the CVC can be left in situ and used without any adverse effects, keeping in mind that left-sided SVC can directly drain into the left atrium (8\%); hence, there is increased risk of systemic air or particulate emboli. Second, left SVC may be associated with a wide variety of other cardiac defects such as single atrium, ventricular septal defect, and patent ductus arteriosus.

Therefore, we conclude that when CVC is along the left border of mediastinum, the possibility of PSLVC should be kept in mind, along with the possibility of it being in one of the tributaries of brachiocephalic vein. If PLSVC is confirmed, it can be left in situ and used for long-term infusion.

\section{Financial support and sponsorship}

Nil.

\section{Conflicts of interest}

There are no conflicts of interest.

\section{REFERENCES}

1. Gibson F, Bodenham A. Misplaced central venous catheters: Applied anatomy and practical management. Br J Anaesth 2013;110:333-46.

2. Ghosh S, Dewan H, Bhattacharyya S. A rare malposition of the thoracic venous catheter introduced via the left internal jugular vein. Indian J Crit Care Med 2008;12:201-3.

3. Ghatak T, Azim A, Baronia AK, Muzaffar SN. Malposition of central venous catheter in a small tributary of left brachiocephalic vein. J Emerg Trauma Shock 2011;4:523-5.

4. Tong MK, Siu YP, Ng YY, Kwan TH, Au TC. Misplacement of a right internal jugular vein haemodialysis catheter into the mediastinum. Hong Kong Med J 2004;10:135-8.

5. Goyal SK, Punnam SR, Verma G, Ruberg FL. Persistent left superior vena cava: A case report and review of literature. Cardiovasc Ultrasound 2008;6:50.

6. Cormier MG, Yedlicka JW, Gray RJ, Moncada R. Congenital anomalies of the superior vena cava: ACT study. Semin Roentgenol 1989;24:77-83.

7. Azocar RJ, Narang P, Talmor D, Lisbon A, Kaynar AM. Persistent left superior vena cava identified after cannulation of the right subclavian vein. Anesth Analg 2002;95:305-7.

8. Higgs AG, Paris S, Potter F. Discovery of left-sided superior vena cava during central venous catheterization. Br J Anaesth 1998;81:260-1. 